\title{
Cell-Specific Protective Signaling Induced by the Novel AT2R-Agonist NP-6A4 on Human Endothelial and Smooth Muscle Cells
}

\author{
Ryan Toedebusch ${ }^{1,2}$, Anthony Belenchia ${ }^{2,3}$ and Lakshmi Pulakat ${ }^{1,2,3 *}$ \\ ${ }^{1}$ Department of Medicine, University of Missouri, Columbia, MO, United States, ${ }^{2}$ Dalton Cardiovascular Research Center, \\ University of Missouri, Columbia, MO, United States, ${ }^{3}$ Department of Nutrition and Exercise Physiology, University \\ of Missouri, Columbia, MO, United States
}

OPEN ACCESS

Edited by:

Issy Laher,

University of British Columbia,

Canada

Reviewed by:

Pascal Bernatchez,

University of British Columbia,

Canada

Tracey Gaspari,

Monash University, Australia

John D. Imig,

Medical College of Wisconsin

United States

*Correspondence:

Lakshmi Pulakat

pulakat|@health.missouri.edu

Specialty section:

This article was submitted to Cardiovascular and Smooth Muscle

Pharmacology,

a section of the journal

Frontiers in Pharmacology

Received: 23 May 2018

Accepted: 30 July 2018

Published: 21 August 2018

Citation:

Toedebusch R, Belenchia A and Pulakat L (2018) Cell-Specific

Protective Signaling Induced by the Novel AT2R-Agonist NP-6A4 on Human Endothelial and Smooth Muscle Cells.

Front. Pharmacol. 9:928. doi: 10.3389/fphar.2018.00928
Cardiovascular disease incidence continues to rise and new treatment paradigms are warranted. We reported previously that activation of Angiotensin II receptor (encoded by the X-linked Agtr2 gene) by a new peptide agonist, NP-6A4, was more effective in protecting mouse cardiomyocyte $\mathrm{HL}-1$ cells and human coronary artery vascular smooth muscle cells (hCAVSMCs) from acute nutrient deficiency than other drugs tested. To elucidate further the protective effects of NP-6A4 in human cells, we studied the effects of NP-6A4 treatment on functions of human coronary artery endothelial cells (hCAECs), and hCAVSMCs. In hCAVSMCs, NP-6A4 (1 $\mu \mathrm{M})$ increased Agtr2 mRNA (sixfold, $p<0.05$ ) after 12-h exposure, whereas in hCAECs, significant increase in Agtr2 mRNA (hCAECs: eightfold) was observed after prolonged exposure. Interestingly, NP6A4 treatment ( $1 \mu \mathrm{M}, 12 \mathrm{~h})$ increased AT2R protein levels in all human cells tested. Pre-treatment with AT2R-antagonist PD123319 $(20 \mu \mathrm{M})$ and anti-AT2R siRNA (1 $\mu \mathrm{M})$ suppressed this effect. Thus, NP-6A4 activates a positive feedback loop for AT2R expression and signaling in hCAVSMCs and hCAECs. NP-6A4 (1-20 $\mu \mathrm{M})$ increased cell index (Cl) of hCAVSMCs as determined by real time cell analyzer (RTCA), indicating that high concentrations of NP-6A4 were not cytotoxic for hCAVSMCs, rather promoting better cell attachment and growth. Seahorse Extracellular Flux Assay revealed that NP6A4 (1 $\mu \mathrm{M})$ treatment for 7 days increased whole cell-based mitochondrial parameters of hCAVSMCs, specifically maximal respiration $(p<0.05)$, spare respiratory capacity $(p<0.05)$ and ATP production $(p<0.05)$. NP-6A4 (1 $\mu \mathrm{M} ; 7$ days) also suppressed Reactive Oxygen Species (ROS) in hCAVSMCs. Exposure to Doxorubicin (DOXO) (1 $\mu \mathrm{M})$ increased ROS in hCAVSMCs and this effect was suppressed by NP-6A4 (1 $\mu \mathrm{M})$. In hCAECs grown in complete medium, NP-6A4 (1 $\mu \mathrm{M})$ and Ang II $(1 \mu \mathrm{M})$ exerted similar changes in Cl. Additionally, NP-6A4 (5 $\mu \mathrm{M}$ : $12 \mathrm{~h}$ ) increased expression of eNOS (sixfold, $p<0.05$ ) and generation of nitric oxide (1.3-fold, $p<0.05)$ in hCAECs and pre-treatment with PD123319 (20 $\mu \mathrm{M})$ suppressed this effect partially (65\%). Finally, NP-6A4 decreased phosphorylation of Jun-N-terminal kinase, implicated in apoptosis of ECs in atherosclerotic sites. Taken together, NP-6A4, through its ability to increase AT2R expression and signaling, exerts different cell-specific protective effects in human VSMCs and ECs. 


\section{INTRODUCTION}

Cardiovascular disease (CVD) is the leading cause of death in both men and women worldwide (World Health Organization [WHO], 2017). The WHO estimated that 17.7 million people died from CVD, accounting for $31 \%$ of all global deaths in 2015 (World Health Organization [WHO], 2017). The reninangiotensin system (RAS) and angiotensin II (Ang II) play a pivotal role in normal cardiovascular physiology, including regulating systemic blood pressure, renal blood flow, and glomerular filtration rate (Inagami, 1994; Gul et al., 2012; Borghi et al., 2015). Chronic pathologies such as hypertension, obesity, diabetes, and metabolic syndrome are accompanied by dysregulation of RAS, and subsequent increased signaling via the Ang II type 1 receptor (AT1R). AT1R activation plays a major role in pathophysiological effects, including; vasoconstriction, fibrosis, oxidative stress via increased ROS, inflammation, and pathological remodeling of cardiovascular, cerebrovascular and renal tissues (Sadoshima and Izumo, 1993; Widdop et al., 2003; Ferrario and Strawn, 2006). Consequently, drugs that inhibit Ang II synthesis or block AT1R-signaling are the standard of care for diseases where RAS over-activation is an underlying cause.

However, Ang II also binds and activates a second receptor, AT2R, encoded by the X-linked Agtr2 gene. Like AT1R, AT2R is a G-protein coupled receptor; but shares only $34 \%$ homology with AT1R (Kambayashi et al., 1993; Mukoyama et al., 1993). AT2R expression, which is high in multiple tissues during fetal development, is reduced in adult tissues and primarily seen in renal, neurological and cardiovascular systems in adult rats (Wang et al., 1998; Miyata et al., 1999). An increase in AT2R expression is observed in response to injury and pathophysiological remodeling (Masaki et al., 1998; Akishita et al., 2000; Li et al., 2005; Altarche-Xifro et al., 2009; Curato et al., 2010) indicating a critical role for AT2R in tissue repair and regeneration. However, mechanisms underlying this effect are not fully understood.

AT2R inhibits AT1R-mediated increase in inositol triphosphate by interacting with the third intracellular loop of AT1R (Kumar et al., 2002; Xu et al., 2014), which in turn, leads to vasodilation, anti-fibrotic, anti-proliferative, and anti-inflammatory effects (Widdop et al., 2003; Jones et al., 2008; Ludwig et al., 2012). Transgenic overexpression of AT2R promotes cardiac repair after myocardial infarction in mice $(\mathrm{Xu}$ et al., 2014). Chronic activation of AT2R renders renal protection in diabetic rats (Ali et al., 2013; Xu et al., 2014), and neuroprotection in hypertensive rats (McCarthy et al., 2014). Increased AT2R expression is seen in the vasculature of female mice and heart tissues of female rats compared to their male counterparts and this sex difference in AT2R expression is implicated in increased cardiovascular protection in females (Okumura et al., 2005; Sampson et al., 2008; Lum-Naihe et al., 2017). It is accepted that many of the beneficial effects of AT1R blockers (ARBs) are due to increases in the amount of bioavailable Ang II, which binds to and activates AT2R receptors (Oishi et al., 2006).

Although ARBs are used widely in the treatment of CVD, meta-analyses of randomized clinical trials suggest that ARBs are not as effective as expected in preventing pathologic remodeling, fibrosis and cardiomyopathy (Axelsson et al., 2015, 2016). Despite the potential of AT2R to promote cardiovascular repair, to date there are no approved AT2R agonists to treat CVD or its comorbidities. Compound 21, a non-peptide AT2R agonist, is an emerging drug for the treatment of idiopathic pulmonary fibrosis and has been shown to offer protection in various tissues including brain (McCarthy et al., 2014; Fouda et al., 2017), vasculature (Chow et al., 2016), kidney (Pandey and Gaikwad, 2017), and heart (Gao et al., 2014) in various rodent disease models. One major challenge in using AT2R agonists to treat CVD is the reduced expression of AT2R in adult tissues, particularly in males. Studies in rodent models have shown that transgenic overexpression of AT2R is beneficial in cardiac repair. However, there are no reports that suggest Compound 21 increases AT2R mRNA or protein expression, limiting its protective benefits.

One important beneficial effect of AT2R activation is mediated through endothelial nitric oxide synthase (eNOS) and subsequent increases in nitric oxide (NO) (Nguyen Dinh Cat et al., 2013; Padia and Carey, 2013). NO is responsible for numerous beneficial functions due to its actions as a potent vasodilator, pro-survival, anti-inflammatory, and antioxidant agent. Cardiac AT2R activation has been associated with NOmediated downstream benefits (Zhu et al., 2010), including vasodilation (Yayama and Okamoto, 2008) and attenuation of fibrosis (Kurisu et al., 2003). Compound 21 increased NO within the renal interstitial fluid in a model of type 1 diabetes (Matavelli et al., 2015) and in human aortic endothelial cells (Peluso et al., 2018).

NP-6A4 is a patent-pending peptide agonist from Novopyxis Inc. (Boston, MA, United States) which has garnered FDA's Orphan Drug designation for the treatment of pediatric cardiomyopathy. We reported previously that NP-6A4 could protect mouse HL-1 cardiomyocytes and human coronary artery vascular smooth muscle cells from acute nutrient deficiency (Mahmood and Pulakat, 2015). To elucidate further the translational potential of NP-6A4, we investigated signaling activated by NP-6A4 in human ECs from two different origins, coronary artery and umbilical vein and hCAVSMCs when grown in complete medium. We report for the first time that NP-6A4 increases Agtr 2 mRNA and AT2R protein in human vascular cells, albeit the effects of NP-6A4 are in a cell-specific manner. Additionally, we show that NP-6A4 activates protective signaling mechanisms in human ECs that may play a role in reducing atherosclerosis and promoting cardioprotective signaling.

\section{MATERIALS AND METHODS}

\section{Cell Culture and Reagents}

All cells were grown at $37^{\circ} \mathrm{C}$ and $5 \% \mathrm{CO}_{2}$. hCAVSMCs (GIBCO - Invitrogen Cell culture, Carlsbad, CA, United States) were cultured in Medium 231 supplemented with Smooth Muscle Growth Supplement (Life Technologies). hCAECs (Cell Applications, Inc.) were cultured in MesoEndo Cell Growth Medium (Cell Applications, Inc.). Human Umbilical Vein Endothelial Cells (hUVECs - GIBCO-Invitrogen Cell culture, 
Carlsbad, CA, United States) were cultured in Medium 200 supplemented with Low Serum Growth Supplement (Life Technologies). PD123319 (AT2R antagonist) and Losartan (AT1R antagonist) were purchased from Tocris Bioscience (Bristol, United Kingdom). NP-6A4 was a gift from Novopyxis Inc. (Boston, MA, United States). All experiments were performed on cells between passage number three and six. For collection, cells were rinsed twice with ice-cold PBS, scraped, centrifuged at $180 \times g$, and flash frozen with liquid nitrogen for subsequent assays.

\section{RNA Isolation for qRT-PCR and DNA Isolation}

Total RNA was isolated using the Direct-zol MiniPrep kit (Zymo Research, United States) according to manufacturer's specifications, and DNase treatment was carried out on the column before RNA elution. Using one microgram purified RNA, cDNA was reverse transcribed using the High-Capacity cDNA Reverse Transcription Kit (Thermo Fisher - Applied Biosystems). Predesigned and validated TaqMan probes (Agt2r Assay ID: Hs02621316_s1 and Agtr1 Assay ID: Hs05043708_s1) and $2 \mathrm{X}$ master mix were obtained from Thermo Fisher (Rockford, IL, United States). qRT-PCR was performed in triplicate using $200 \mathrm{ng}$ cDNA. mRNA expression values were quantified by the $2^{-\Delta \Delta \mathrm{Ct}}$ method, whereby $\Delta \mathrm{CT}=18 \mathrm{~S} \mathrm{Ct}-$ gene of interest Ct. DNA was isolated using a commercially available kit for assaying mitochondrial DNA copy number (Detroit R\&D Inc., Detroit, MI, United States), and provided mitochondrial and nuclear primers were used to generate the ratio of $\mathrm{mtDNA} /$ nuclear DNA using the following formula: $\Delta C t 1=C t($ mitochondrial control $)-C t$ (nucleus control)

\section{siRNA Mediated Knockdown of AT2R}

In order to use an additional measure to antagonize and knockdown AT2R receptor expression, we utilized AT2Rtargeted siRNA. Briefly, AGTR2 Silencer Select Pre-designed siRNA (ID: s1184, Cat\#: 4392420) and Silencer Select Negative Control \#1 siRNA (Cat\#: 4390843) were purchased from Ambion (Ambion, United States). Transfection was carried out in hCAECs using siPORT Amine transfection reagent (Invitrogen - Thermo Fisher Scientific). Briefly, cells were seeded in 24-wells plates (treated with $12.5 \mu \mathrm{g} / \mathrm{ml}$ bovine fibronectin in $0.02 \%$ gelatin solution), and $50 \mu \mathrm{l} 1: 1$ solution (siPORT Amine + OPTI-MEM: $1 \mu \mathrm{M}$ siRNA or siRNA-scramble + OPTIMEM) was added to respective wells for $24 \mathrm{~h}$. NP-6A4 was added immediately after transfection. After $24 \mathrm{~h}$, cells were fixed in $4 \%$ PFA and subjected to immunofluorescence protocol described below.

\section{Immunofluorescence}

Immunofluorescence was used to determine the changes in the expression of AT2R protein in hCAVSMC, hCAEC, and hUVEC in response to NP-6A4 treatment. All cells were grown on cover slips in 24-well plates treated with fibronectin in appropriate media. PD123319 was applied $(20 \mu \mathrm{M}) 20 \mathrm{~min}$ before adding NP-6A4 (1 $\mu \mathrm{M})$. NP-6A4-containing medium was replenished twice during 12-h treatment, to ensure availability of the drug. After 12-h treatments, coverslips were washed with HBSS (Sigma), fixed with $4 \%$ paraformaldehyde for 15 min at room temperature, permeabilized with $0.5 \%$ Triton X-100, washed with HBSS buffer, and blocked with $1 \%$ bovine serum albumin (BSA) (Jackson ImmunoResearch), along with $10 \%$ goat serum (Sigma) in PBS-T (1 mL Tween-20/L). Coverslips were incubated with anti-AT2R antibody (Abcam) (1:500 dilution) overnight at $4^{\circ} \mathrm{C}$, washed with HBSS and then incubated with Alexa Fluor 488 goat anti-rabbit antibody (Invitrogen, Inc.) (1:200 dilution) for $1 \mathrm{~h}$ at room temperature. Coverslips were washed with HBSS and mounted with Fluoroshield with DAPI (4',6-diamidino-2-phenylindole) (Sigma-Aldrich). Microscopy was performed using a Leica DMI 4000B inverted confocal microscope using Leica Application Suite software. Imaging was done at $20 \times$ magnification using oil immersion. Each experimental condition was done in triplicate and $>50$ cells per replicate were recorded and fluorescence intensity was determined using ImageJ software (NIH, Bethesda, MD, United States).

\section{xCELLigence Real Time Cellular Analysis (RTCA)}

RTCA DP (ACEA Biosciences) uses non-invasive electrical impedance monitoring to quantify cell proliferation, morphology change, and attachment quality in real-time. E-plates treated with fibronectin were used for all experiments. For each cell type, pilot studies determined adequate seeding density, expected CI, and growth rates. Briefly, after seeding of cells, plates were incubated in a $37^{\circ} \mathrm{C}$ incubator at $5 \% \mathrm{CO}_{2}$. Cells were allowed to equilibrate in normal media until the cell index (CI) became stable and started to rise. Then, media were changed, drugs were added and changes in CI were monitored every $15 \mathrm{~min}$. Data reported is from a minimum of two independent E-plate experiments (different passages of cells) and in each experiment, a given drug treatment was performed in triplicates and in wells at different locations to ensure that the data was not affected by positional effects.

\section{Seahorse Extracellular Flux Assay}

Oxygen consumption rates (OCR) were measured using the Seahorse XFe24 Analyzer (Seahorse Biosciences, Agilent, United States). Seahorse Sensor cartridge was incubated overnight in XF calibrant at $37^{\circ} \mathrm{C}$ per manufacturer instructions. Briefly, on the day of the assay, hCAVSM cells were seeded on Seahorse 24-well plates at a density of $1.2 \times 10^{5}$ cells per well. Seahorse media (Seahorse Biosciences, Agilent, United States) was used with Glucose $(10 \mathrm{mM})$, Sodium pyruvate $(1 \mathrm{mM})$, and Glutamine $(2 \mathrm{mM})$ added fresh and warmed to $37^{\circ} \mathrm{C}$. Cells were equilibrated to $37^{\circ} \mathrm{C}$ and the Seahorse XF Mitochondria Stress Test Kit was used per manufacturers protocol. Initially, appropriate pilot experiments were carried out to ensure correct concentrations of Oligomycin $(1 \mu \mathrm{M})$ and FCCP $(0.5 \mu \mathrm{M})$, and adequate cell seeding density $\left(1.2 \times 10^{5}\right)$ for hCAVSMCs. 


\section{Reactive Oxygen Species Detection (ROS)}

Using the commercially available DCFDA/H2DCFDA Cellular Reactive Oxygen Species Detection Assay Kit (Abcam cat \#ab113851), ROS was assayed in quadruplicates after background correction. NP-6A4 pretreated cells received daily medium change with NP-6A4 $(1 \mu \mathrm{M})$ for 7 days prior to experiment. Briefly, $2.5 \times 10^{3}$ hCAVSMC were seeded per well on a 96-well fibronectin treated plate, and allowed to adhere overnight. The next day, cells were washed and incubated in $40 \mu \mathrm{M}$ DCFDA dye for $45 \mathrm{~min}$ at $37^{\circ} \mathrm{C}$. Cells were then incubated in either media supplement with $1 \mu \mathrm{M}$ doxorubicin or $1 \mu \mathrm{M}$ NP-6A4 for $1 \mathrm{~h}$. Cells were washed with media and read on fluorescent plate reader at 485/535 emission/excitation.

\section{Nitric Oxide Level Quantification Using DAF-FM Staining}

We used the cell permeant reagent 4-Amino-5-Methylamino$2^{\prime}, 7^{\prime}$-Difluorofluorescein Diacetate (DAF-FM Diacetate, Thermo Fisher Scientific) to quantify NO generation in hCAECs. DAF-FM remains non-fluorescent until reacting with $\mathrm{NO}$, at which time it forms a fluorescent benzotriazole. Briefly, endothelial cells were seeded on fibronectin treated slides and subsequently treated with either NP-6A4 (5 $\mu \mathrm{M})$ or NP-6A4 $(5 \mu \mathrm{M})+\operatorname{PD} 123319(20 \mu \mathrm{M})$ for $24 \mathrm{~h}$. Cells were then treated with $1 \mu \mathrm{M}$ DAF-FM in DMEM (no phenol red) for $30 \mathrm{~min}$ at $37^{\circ} \mathrm{C}$. Next, cells were washed twice with DMEM (no phenol red), and incubated at $37^{\circ} \mathrm{C}$ for $30 \mathrm{~min}$ to complete the DAF-FM reaction. Lastly, cells were fixed with ice-cold $4 \%$ paraformaldehyde and stained with Wheat Germ Agglutinin (WGA) conjugated with Alexa Fluor 555 (Thermo Fisher Scientific), in order to define cell borders. Slides were then visualized using a Leica DMI 4000B inverted confocal microscope using Leica Application Suite software. Imaging was done at $63 \times$ magnification using oil immersion. Each experimental condition was done in triplicate and $>30$ cells per replicate were recorded and fluorescence intensity was determined using ImageJ software (NIH, Bethesda, MD, United States).

\section{Western Blotting}

Previously frozen cell pellets were homogenized with RIPA buffer [50 mM Tris- $\mathrm{HCl}$ ( $\mathrm{pH}$ 8.0), $150 \mathrm{mM} \mathrm{NaCl}$, $1 \%$ NP-40, $0.5 \%$ sodium deoxycholate, 1\% SDS, $1 \times$ protease/phosphatase inhibitor cocktail (Thermo Scientific, Rockford, IL, United States)]. The homogenate was rotated for $30 \mathrm{~min}$ at $4^{\circ} \mathrm{C}$ and centrifuged at $12,000 \mathrm{~g}$ for $10 \mathrm{~min}$, and the resultant supernatant was obtained for Western blotting. Protein concentrations were determined using the BCA assay (Pierce Biotechnology, Rockford, IL, United States), and $15 \mu \mathrm{g}$ of protein in loading buffer was loaded onto SDS-PAGE gels. Next, proteins were transferred to nitrocellulose membranes, and all blots were incubated with Ponceau S (Sigma, St Louis, $\mathrm{MO}$, United States) to validate equal loading across samples and lanes. Membranes were blocked overnight at $4^{\circ} \mathrm{C}$ in $5 \%$ fat free milk. Primary antibodies (Abcam) were rabbit polyclonal AT2R at 1:1000, mouse monoclonal eNOS at 1:500, rabbit polyclonal phospho-eNOS (Ser1177) at 1:1000. All antibodies were diluted in Tris-buffered saline + Tween- 20 with $5 \%$ bovine serum albumin and applied to membrane overnight at $4^{\circ} \mathrm{C}$. The following day, horseradish peroxidase-conjugated secondary antibody (1:1,000; Cell Signaling Technology, Danvers, MA, United States) was applied for $3 \mathrm{~h}$ at room temperature, and ECL substrate (Thermo Fisher) was applied immediately prior to exposure. Band densitometry was performed using Image Lab (Bio-Rad).

\section{Milliplex MAP Multi-Pathway Total and Phospho- Magnetic Bead 9-Plex Assay}

hCAECs were grown to $\sim 70 \%$ confluence in T-75 flasks (Corning Inc, Corning, NY, United States), at which time cells were treated with either; NP-6A4 (5 $\mu \mathrm{M})$, , or control medium for $24 \mathrm{~h}$. PD123319 was added $20 \mathrm{~min}$ prior to NP-6A4 and a medium change with appropriate drugs was done after $12 \mathrm{~h}$ of treatment to ensure continuous drug exposure. Briefly, cells were placed on ice, washed twice with ice-cold PBS and lysed using $300 \mu \mathrm{l}$ of manufacturers lysis buffer (with appropriate phosphatase inhibitors added fresh), scraped, collected, and agitated at $4^{\circ} \mathrm{C}$ for $15 \mathrm{~min}$. Next, lysates were sterile filtered using EMD Millipore filter-tubes (Catalog \# UFC30DV00 - Millipore Sigma, Burlington, MA, United States). Lysate was used for two separate assays, one for total proteins and a second for phosphorylated proteins (MILLIPLEX MAP Multi-Pathway Magnetic Bead CellSignaling 9-Plex; Millipore Sigma). The following probes were included as part of the kits: Total proteins and phosphorylated proteins for (phosphorylated residues in parenthesis); cAMP response element binding [CREB, (pS133)], c-Jun N-terminal kinase [JNK, (pT183/pY185)], nuclear factor kappa -light chain -enhancer of activated B cells [NFkB, (pS536)], p38 mitogen activated protein kinases [p38, (pT180/pY182)], p44/42 mitogen activated protein kinase [ERK1/2, (pT185/pY187)], protein kinase B [Akt, (pS473)], ribosomal protein S6 kinase beta [p70 S6K, (pT412)], signal transducer and activator of transcription 3 [STAT3, (pS727)], and signal transducer and activator of transcription 5 [STAT5A/B, (pY694/699)]. Assay was carried out following manufacturers protocol and fluorescence was assessed using $\mathrm{xMAP}^{\circledR}$ technology on $\mathrm{MAGPIX}^{\circledR}$ platform (Luminex, Austin, TX, United States). Mean Fluorescent Intensities were obtained in triplicate for each sample and compared between groups.

\section{Statistics}

All analytical procedures were performed using Microsoft Excel v2011 (Microsoft, Redmond, WA, United States), Prism GraphPad 7 (GraphPad Software, CA, United States), and SAS 9.4 (SAS Institute Inc., Cary, NC, United States). Values are presented as means \pm standard error of the mean (SEM). Significance for all analyses was set with a $p$-value of 0.05 . Student's $t$-test was used to assess between group differences for outcome measurements in studies involving two treatment groups. Differences in outcome variables for studies involving more than two treatment groups and/or timepoints were assessed by one-way or two-way ANOVA, as indicated in figure legends. 


\section{RESULTS}

\section{NP-6A4 Treatment Increases Agtr2 mRNA and AT2R Protein in Human Cardiovascular Cells}

To further elucidate the potential protective mechanisms of NP$6 \mathrm{~A} 4$ in human cardiovascular cells, we assessed the effects of NP-6A4 treatment on hCAVSMC, hCAEC, and hUVECs. Agtr2 mRNA has a reported half-life of $\sim 18$ h (Kijima et al., 1995), implying that any change should be detectable within the 12-h time window. In hCAVSMCs, NP-6A4 $(1 \mu \mathrm{M})$ increased Agtr2 mRNA (sixfold, $p<0.05$ ) after a 12-h treatment (Figure 1A) and the effect remained after 7-days of $1 \mu \mathrm{M} \mathrm{NP}-6 \mathrm{~A} 4$ (Figure 1A), while no change in AT1R expression was overserved (Figure 1B). Given that the half-life of Agtr2 mRNA is in the 12-18$\mathrm{h}$ range, we assessed AT2R protein expression after $12-\mathrm{h}$ of NP-6A4 treatment. AT2R protein increase was detected using immunofluorescent staining after 12-h of NP-6A4 treatment, while pretreatment with AT2R-antagonist PD123319 attenuated NP-6A4-mediated increase in AT2R protein levels in hCAVSMCs (Figures 1C,D). These observations indicated that NP-6A4 acting through the AT2R induces a positive feedback loop to increase Agtr 2 mRNA and AT2R protein expression and signaling.

Next, we tested whether NP-6A4-mediated increases in Agtr2 mRNA and AT2R protein also occurs in human endothelial cells using hCAECs and hUVECs. While a 12-h NP-6A4 (1 $\mu \mathrm{M})$ treatment of hCAECs (Figure 2A) was not sufficient to increase Agtr2 mRNA, a chronic treatment for 7 days with NP-6A4
$(1 \mu \mathrm{M})$ resulted in a twofold increase in Agtr2 mRNA in these cells (Figure 2A). However, a 12-h treatment with NP6A4 $(1 \mu \mathrm{M})$ was sufficient to increase AT2R protein levels by twofold in hCAECs (Figures 2C,D). Thus, the time course to increase Agtr 2 mRNA by NP-6A4 differed between hCAVSMCs and hCAECs. To confirm further that the effects of NP-6A4 are mediated through the AT2R protein expression, we transfected hCAECs with an anti-AT2R siRNA prior to the treatment with NP-6A4 (1 $\mu \mathrm{M})$. NP-6A4 treatment did not increase AT2R protein levels in hCAECs transfected with anti-AT2R siRNA (Figures 2C,D) indicating that NP-6A4 needs AT2R protein expression to activate a positive feedback loop.

Similar findings were also observed in hUVECs; Agtr 2 mRNA levels did not change in hUVECs after 12-h NP-6A4 (1 $\mu \mathrm{M})$ treatment, whereas 7-days of NP-6A4 treatment resulted in an almost eightfold increase in Agtr 2 mRNA levels in these cells (Figure 3A). However, as in hCAECs, a 12-h NP-6A4 (1 $\mu \mathrm{M})$ treatment was sufficient to increase AT2R protein in hUVECs (Figures 3C,D). Moreover, pre-treatment with AT2R antagonist PD123319 before the addition of NP-6A4, attenuated NP6A4-induced increase in AT2R protein expression in hUVECs. Collectively, these observations suggest that in human coronary artery VSMCs and ECs, NP-6A4 increases Agtr2 mRNA and AT2R protein expression, albeit the time course for this effect can be cell-specific.

Previous studies have indicated that AT2R agonist CGP42112A suppresses AT1R mRNA expression (Yang et al., 2012). Therefore, we tested whether NP-6A4 treatment modulated expression of the AT1R mRNA in human coronary
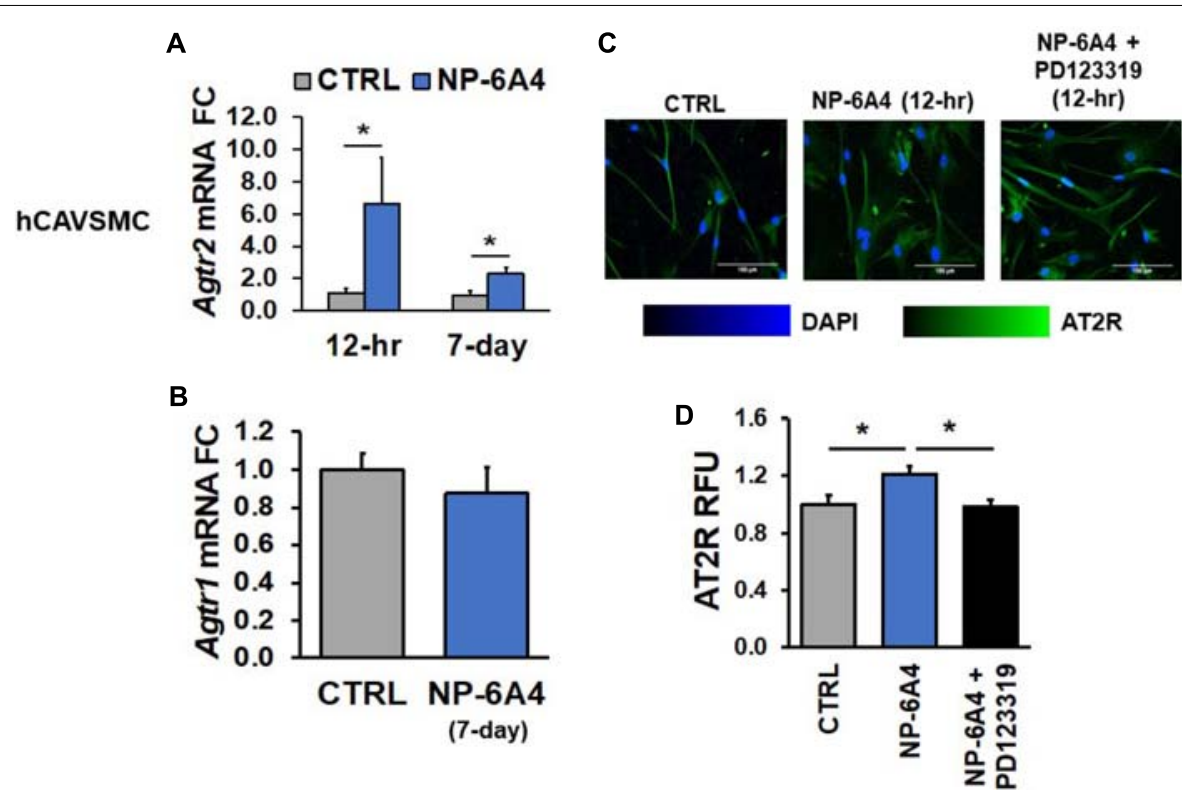

FIGURE 1 | NP-6A4 increased Agtr2 mRNA and AT2R protein expression in hCAVSMC. (A) $1 \mu$ M NP-6A4 for 12-h and 7-day increased Agtr2 mRNA expression. (B) No change in Agtr1 mRNA was detected after $1 \mu \mathrm{M} \mathrm{NP}-6 \mathrm{~A} 4$ for 7 -days. $n=$ at least three biological replicates and PCR replicates, respectively, for these experiment. (C) Representative images of hCAVSMCs treated with $1 \mu \mathrm{M}$ NP-6A4 for 12-h. Blue indicates DAPI stained nuclei and green AT2R. Merged images are shown for all experimental conditions. (D) Quantification of relative fluorescent units (RFU) shows increased expression of AT2R protein after $1 \mu M$ NP-6A4 treatment for 12-h and $20 \mu \mathrm{M}$ PD123319 prevented this increase. Immunofluorescent experiments consisted of quantification of $>50$ cells from triplicates per experiment. *Indicates $p<0.05$ using One-way ANOVA. hCAVSMC, human coronary artery vascular smooth muscle cell; FC, fold change. 


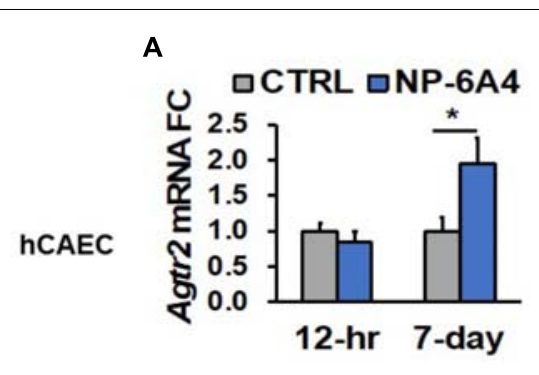

B

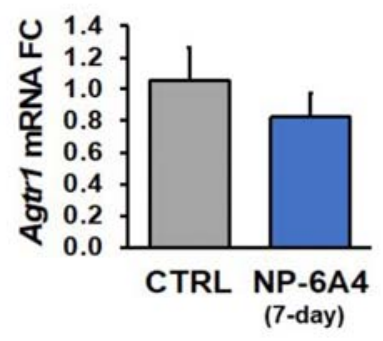

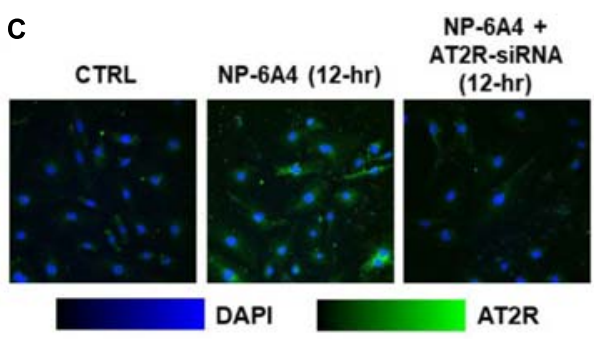

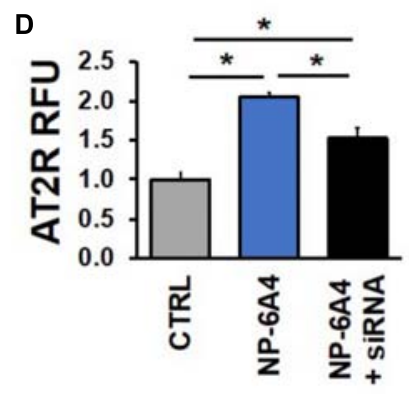

FIGURE 2 | NP-6A4 increased Agtr2 mRNA and AT2R protein expression in hCAECs. (A) $1 \mu \mathrm{M}$ NP-6A4 for 12-h showed no difference in Agtr2 mRNA, while 7-day treatment increased Agtr2 mRNA expression twofold. (B) No change in Atgr1 was detected after $1 \mu \mathrm{M}$ NP-6A4 for 7-days. $n=$ at least three biological replicates and PCR replicates, respectively, for these experiment. (C) Representative images of hCAECs treated with $1 \mu \mathrm{M} \mathrm{NP-6A4}$ for 12 -h. Blue indicates DAPI stained nuclei and green AT2R. Merged images are shown for all experimental conditions. (D) Quantification of relative fluorescent units (RFU) shows increased expression of AT2R protein after $1 \mu \mathrm{M}$ NP-6A4 treatment for 12-h. AT2R-siRNA prevented NP-6A4-induced increase in AT2R expression. Immunofluorescent experiments consisted of quantification of $>50$ cells from triplicates per experiment. *Indicates $p<0.05$ using One-way ANOVA. hCAEC, human coronary artery endothelial cell; FC, fold change.
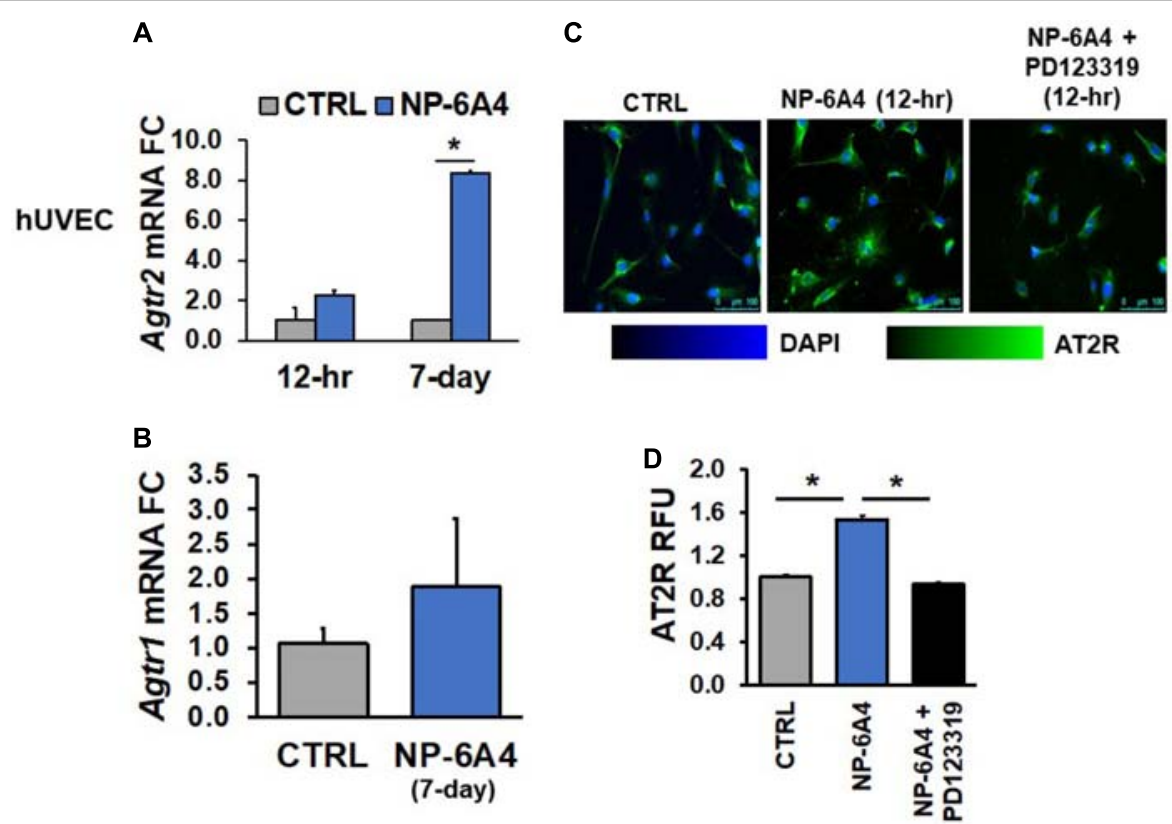

FIGURE 3 | NP-6A4 increased Agtr2 mRNA and AT2R protein expression in hUVEC. (A) $1 \mu$ M NP-6A4 for 12-h showed no difference in Agtr2 mRNA, while 7-day treatment increased Agtr2 mRNA expression eightfold. (B) No change in Atgr1 was detected after $1 \mu \mathrm{M}$ NP-6A4 for 7 -days. $n=$ at least three biological replicates and PCR replicates, respectively, for these experiment. (C) Representative images of hUVECs treated with $1 \mu \mathrm{M}$ NP-6A4 for 12 -h. Blue indicates DAPI stained nuclei and green AT2R. Merged images are shown for all experimental conditions. (D) Quantification of relative fluorescent units (RFU) shows increased expression of AT2R protein after $1 \mu \mathrm{M}$ NP-6A4 treatment for 12-h and $20 \mu \mathrm{M}$ PD123319 prevented this increase. Immunofluorescent experiments consisted of quantification of $>50$ cells from triplicates per experiment. *Indicates $p<0.05$ using One-way ANOVA. hUVEC, human umbilical vein endothelial cell; FC, fold change. 
artery VSMCs and ECs. We did not observe any changes in Agtr1 mRNA after 7-days of NP-6A4 $(1 \mu \mathrm{M})$ treatment in hCAVSMCs, hCAECs and hUVECs (Figures 1B, 2B, 3B).

\section{NP-6A4 Is Not Cytotoxic, Promotes Favorable Growth Conditions, and Enhances Mitochondrial Energetics in hCAVSM Cells}

We reported previously that when hCAVSMCs were grown in medium 231 in nutrient deficient conditions generated by the absence of Smooth Muscle Growth Supplement (SMGS), NP-6A4 (300 $\mathrm{nM}$ ) could improve their viability significantly better than $\beta 1$ adrenergic receptor blockers (atenolol, metoprolol, carvedilol, and nebivolol), losartan and AT2 receptor peptide agonist CGP42112A (Mahmood and Pulakat, 2015). To determine if treatment with higher concentrations of NP-6A4 would exert any cytotoxic effects on hCAVSMCs, we investigated how increasing concentrations of NP-6A4 $(1-20 \mu \mathrm{M})$ would modulate cell index (CI) of hCAVSMCs grown in nutrient-rich medium (medium $231+$ SMGS) for a period of $48 \mathrm{~h}$ using the Real Time Cell Analyzer (RTCA). CI is a quantitative measure of cell number, cell size and cell adhesion. Since we observed that a 7-day treatment of hCAVSMCs grown in nutrient rich medium with NP-6A4 $(1 \mu \mathrm{M})$ did not exhibit any negative growth effects and they retained an increase in Agtr 2 mRNA (Figure 1A), we pre-treated hCAVSMCs for 7 days with NP-6A4 (1 $\mu \mathrm{M})$ before seeding on the E-plate for RTCA assay. hCAVSMCs that were not pretreated with NP-6A4 were used as controls in the experiment and the data in Figure $\mathbf{4 A}$ is presented after normalizing to these control (CTRL) cells (dotted line on Figure 4A). At all points during the time course, all concentrations of NP$6 \mathrm{~A} 4$ induced a steady increase in CI compared to CTRL cells (Figure 4A). The best effect was observed with $20 \mu \mathrm{M}$ NP$6 \mathrm{~A} 4$ that increased the $\mathrm{CI}$ as early as 12-h after exposure (Figure 4A, $p<0.05$ ). Additionally, NP-6A4 pre-treatment alone was sufficient to significantly increase CI vs. CTRL cells after 24 and 48-h treatments (Figure 4A, $p<0.05$ ). Only at $12 \mathrm{~h}$ time point, NP-6A4 pre-treated cells did not exhibit significant change in CI in the absence of NP-6A4. Thus, hCAVSMCs did not exhibit any cytotoxic effects when they were exposed to NP-6A4 for up to nine days (7 days pre-treatment with $1 \mu \mathrm{M} \mathrm{NP}-6 \mathrm{~A} 4$ and 2 days additional exposure to 0,5 , and $20 \mu \mathrm{M}$ doses of NP-6A4), and exhibited favorable growth response to NP-6A4 as evidenced by their increased CI (Figure 4A, $p<0.05$ ). Moreover, the increase in CI by $20 \mu \mathrm{M}$ dose of NP-6A4 was significantly higher than the increase in CI seen with the $5 \mu \mathrm{M}$ dose of NP-6A4 at both the 24 and $48 \mathrm{~h}$ timepoint, indicating that NP-6A4 increased the CI of hCAECs in a dose-dependent manner.

Given the discovery and characterization of a functional mitochondrial renin-angiotensin system (RAS) (Abadir et al., 2011) and relatively little is known regarding AT2R receptor activity at the level of mitochondria, we sought to investigate the ability of NP-6A4 to modulate mitochondrial energetics, specifically oxygen consumption rates, using the Seahorse Extracellular Flux Assay. The XF Cell Mito Stress Test allows for measurement of key parameters of mitochondrial function through direct detection of oxygen consumption rates of cultured cells. hCAVSM cells treated with $1 \mu \mathrm{M}$ NP-6A4 for 1-week showed an increase oxygen consumption rate (Figure 4B), ATP production (Figure $4 \mathrm{C}, p<0.05$ ), maximal respiration (Figure 4D, $p<0.05$ ), and spare respiratory capacity (Figure $4 \mathrm{E}$, $p<0.05)$.

The role of Ang II in activating NADPH oxidase and increasing reactive oxygen species is well established. It is unclear how activation of AT2R modulates reactive oxygen species in hCAVSMCs. Given that mitochondria are important sources of reactive oxygen species (ROS) (Jensen, 1966; Cortassa et al., 2017), we investigated how treatment with NP-6A4 (1 $\mu \mathrm{M})$ for 7 -days modulates ROS levels in hCAVSMCs. The cell-permeant $2^{\prime}, 7^{\prime}$-dichlorodihydrofluorescein diacetate (H2DCFDA) is a chemically reduced form of fluorescein that can be used as an indicator for ROS in cells. Therefore, we stained NP-6A4pretreated and untreated hCAVSMC cells with DCFDA to detect changes in ROS levels. The ROS levels were significantly reduced in NP-6A4 pre-treated hCAVSMCs compared to untreated (CTRL) hCAVSMCs (Figure 5A, $p<0.05$ ).

Doxorubicin (DOXO), a chemotherapeutic agent widely used in cancer treatment, causes significant increases in ROS (Kim et al., 2006; Asensio-Lopez et al., 2017). Since DOXO treatment is known to induce vascular toxicity (Bielak-Zmijewska et al., 2014), we investigated whether DOXO treatment would increase ROS in hCAVSMC. Treatment with $1 \mu \mathrm{M}$ DOXO caused an increase in ROS in CTRL hCAVSMCs compared to untreated cells, however, NP-6A4 pre-treatment suppressed this effect (Figure 5A, $p<0.05$ ). Collectively, these observations suggest that NP-6A4 treatment is effective in reducing ROS levels in hCAVSMCs. We did not see a significant change in mtDNA content in response to NP-6A4 treatment, although a trend was observed (Figure 5B, $p=0.06$ ). Moreover, Immunoblotting analysis of all the oxidative phosphorylation protein complexes in whole cell lysates of NP-6A4-treated and CTRL hCAVSMCs revealed no significant differences in complex I (CI), complex II (CII), complex V (CV), or complex IV (CIV) were observed (Figures 5C,D). Taken together, these data suggest that the increased OCR concomitant with decreased ROS observed after chronic NP-6A4 treatment is likely not the result of increased quantity, but likely a change in the quality and efficacy of the existing mitochondria.

\section{Endothelial Cell Response to NP-6A4 Treatment}

Endothelial cells have a critical role in maintaining vascular health because they play a crucial role in maintaining bioavailability of nitric oxide and proper vasodilation (Prieto et al., 2014; Khaddaj Mallat et al., 2017). Moreover, EC cell death underlies atherosclerotic plaque formation and destabilization (Di et al., 2017). First, we explored the growth characteristics of hCAECS using the RTCA system in an attempt to understand NP-6A4 and its ability to alter general cellular growth characteristics. Interestingly, NP-6A4 and Ang II treatment did not augment the cell index in hCAECs (Figures 6A,B). However, the cell index of hCAECs (Figures 6A,B) was significantly 


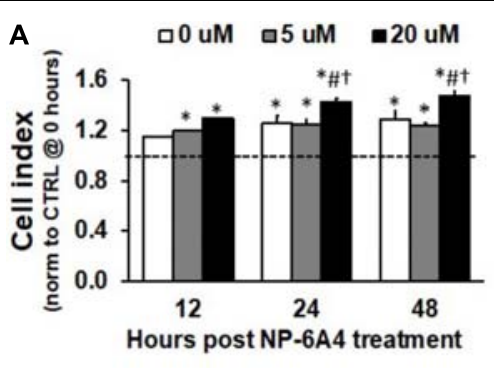

B

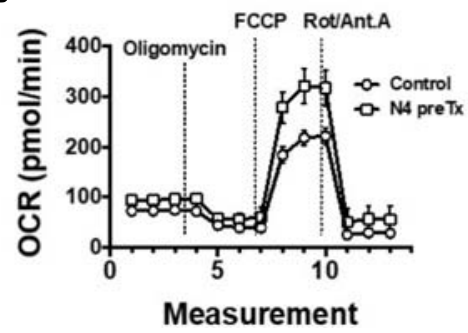

C

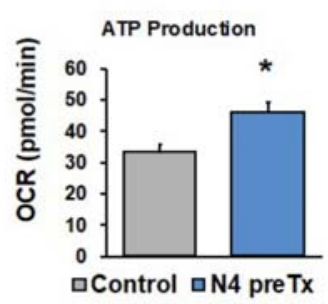

D

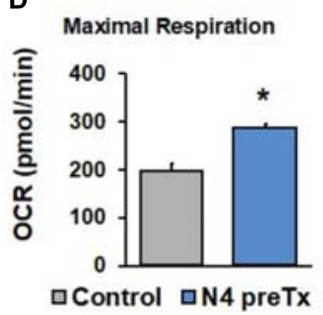

E

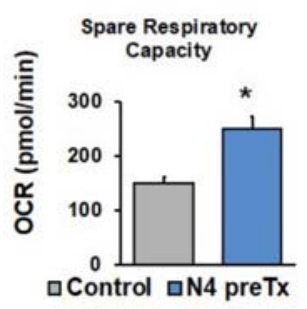

FIGURE 4 | NP-6A4 increased hCAVSMC growth properties and mitochondrial energetics. (A) Cell Index in cells pretreated with NP-6A4 for 7-days and then treated with increasing doses of acute NP-6A4 from 0 to $20 \mu \mathrm{M}$. All doses increased Cl compared to untreated (CTRL) cells. Data were analyzed using a two-way ANOVA

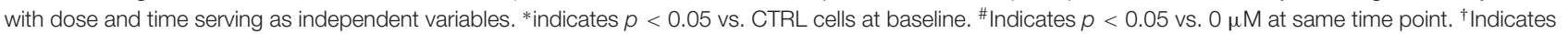
$p<0.05$ vs. $5 \mu \mathrm{M}$ at the same time point. $n=4$ per group. (B) OCR increased after 7-days of $1 \mu \mathrm{M}$ NP-6A4 treatment measured using the Seahorse Extracellular Flux Assay. (C) ATP production was increased after NP-6A4 treatment. (D) Maximal respiration was increased after NP-6A4 treatment. (E) Spare respiratory capacity was increased after NP-6A4 treatment. $n=3$ per group. *Indicates $p<0.05$ using One-way ANOVA. hCAVSMC, human coronary artery vascular smooth muscle cell.

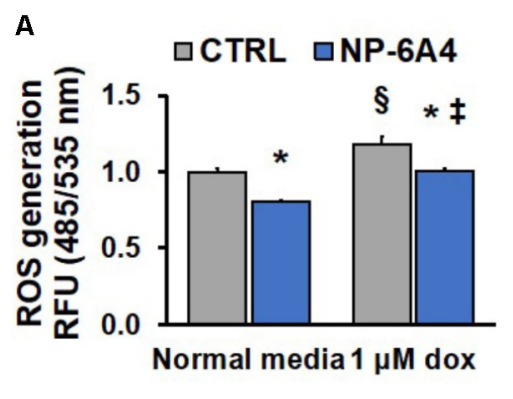

B

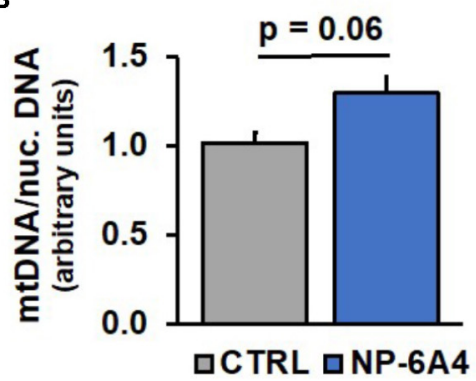

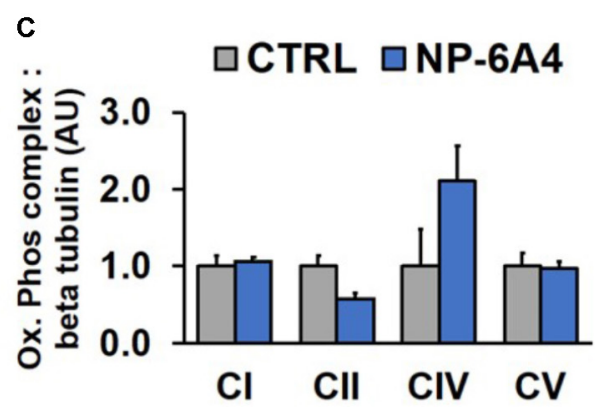

D

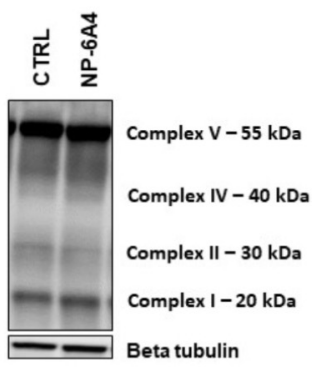

FIGURE 5 | NP-6A4 reduces reactive oxygen species while not altering mitochondrial number in hCAVSMCs. (A) Cellular ROS was increased with $1 \mu \mathrm{M}$ Doxorubicin, while $1 \mu \mathrm{M}$ NP-6A4 reduced ROS generation in both normal media and $1 \mu \mathrm{M}$ Doxorubicin. $n=4$. (B) Mitochondrial DNA was non-significantly increased after 7 days of NP-6A4 treatment. $n=4$. (C) Oxidative phosphorylation complexes quantification of Western Blot images. $n=3$. (D) Representative image of the Western blot for oxidative phosphorylation complexes after 7-days of NP-6A4 treatment. *Indicates $p<0.05$ vs. CTRL using two-tailed Student's $t$-test. ${ }^{\S}$ Indicates $p<0.05$ vs. CTRL cells (normal media). "Indicates $p<0.05$ vs. NP-6A4 preTx cells (normal media). OCR, oxygen consumption rate; hCAVSMC, human coronary artery vascular smooth muscle cell. 

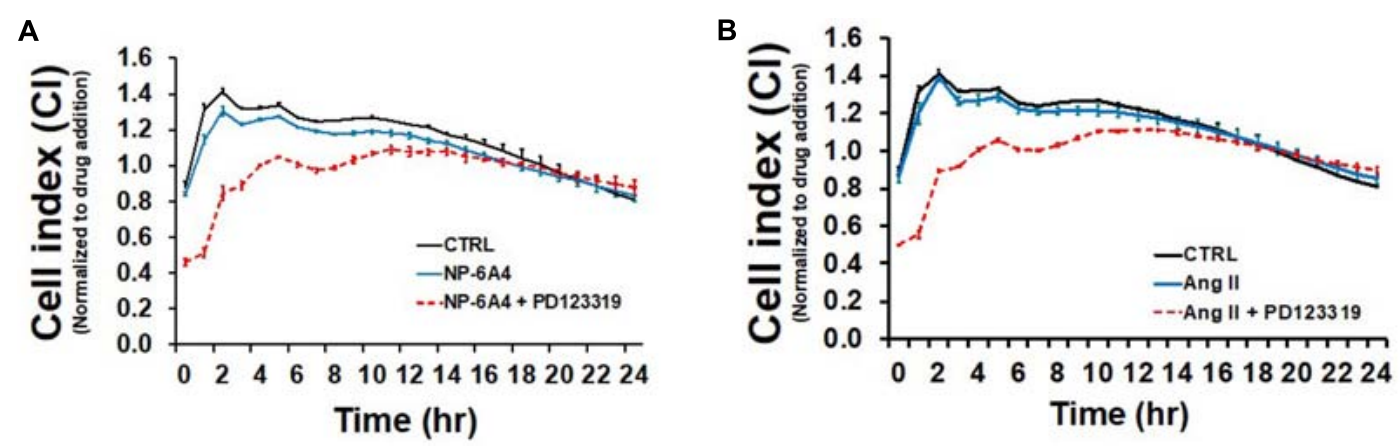

FIGURE 6 | Growth promoting effects of NP-6A4 are similar to Angiotensin II in hCAECs. (A) NP-6A4 did not increase Cl in hCAEC, while AT2R-agonist PD123319 decreased $\mathrm{Cl}$ initially but stabilized within 24-h. (B) Likewise, Ang II did not change Cl compared to normal medium, while PD123319 attenuated Cl at $6 \mathrm{~h}$ post treatment but stabilized within 24-h. $n=4$. Control data is the same in A and B. Cl, cell index; Ang II, angiotensin II; hCAECs, human coronary artery endothelial cells.

decreased $(p<0.05)$ when treated with the AT2R antagonist PD123319 $(20 \mu \mathrm{M})$ before treating with NP-6A4 $(1 \mu \mathrm{M})$ and Ang II (500 nM). This suggests that, to some degree, that AT2R receptor activation plays a role in human coronary artery endothelial cells response in terms of cell proliferation, morphology change, and attachment quality. PD123319 is reported to have off-target effects and its role in increasing abdominal aortic aneurisms in response to Ang II is not via AT2R (Daugherty et al., 2013). Therefore, it is conceivable that use of $20 \mu \mathrm{M}$ PD123319 in our experiments could have exerted some off-target effects that contributed to the eventual increase in the CI of hCAEC in the presence of PD123319. To further confirm that NP-6A4 acted through the AT2R in hCAECs, we transfected the cells with anti-AT2R siRNA for $14 \mathrm{~h}$ before adding NP-6A4 (Figure 7). Transfection with Scrambled siRNA was used as control. Interestingly, the CI of hCAECs transfected with antiAT2R siRNA (labeled siRNA) was found to be lower than those transfected with siRNA-Scrambled (labeled scRNA) before the addition of NP-6A4 (Figures 7A,B). Thus, suppression of AT2R expression was detrimental to the CI of hCAECs. Addition of NP-6A4 significantly increased the CI of hCAECs transfected with scRNA compared to those that did not receive NP-6A4 treatment (Figures 7A,C). However, addition of NP-6A4 did not significantly change the CI of hCAECs transfected with antiAT2R siRNA (labeled siRNA + N4) compared to those that did not receive NP-6A4 treatment (labeled siRNA) (Figures 7A,C). Thus, the effect of NP-6A4 on the CI of hCAECs was abolished by anti-AT2R siRNA.

AT2R activation is reported to increase eNOS expression and NO bioavailability in human endothelial cells (Peluso et al., 2018). To determine whether NP-6A4 exerted similar effects in hCAECs, we investigated expression and phosphorylation levels of eNOS and NO generation in hCAECs treated with $5 \mu \mathrm{M}$ NP-6A4. Preliminary time course experiments confirmed that 24h NP-6A4 $(5 \mu \mathrm{M})$ treatment elicited the largest increase (and detectable) in NO compared to untreated cells (Supplementary Figure 1). Therefore, hCAE cells treated with $5 \mu \mathrm{M}$ NP-6A4 for $24 \mathrm{~h}$ were stained with the cell permeant stain, DAF-FM. NO was significantly increased $(p<0.05)$ compared to control (Figures 8A,B). Interestingly, pretreatment with PD123319
$(20 \mu \mathrm{M})$ prior to NP-6A4 inhibited the increase in NO intensity. This data suggests that AT2R activation is upstream of NO release and imperative for the increased NO after agonist treatment. To confirm the increase in NO levels, we hypothesized that eNOS protein levels would be increased. Immunoblotting of the lysates from hCAECs with or without NP-6A4 $(1 \mu \mathrm{M})$ treatment for $12 \mathrm{~h}$ showed that both total and phosphorylated eNOS proteins were increased in NP-6A4-treated hCAECs (Figures 8C,D, $p<0.05$ ).

Lastly, in an attempt to better understand NP-6A4-AT2Rinduced downstream signaling pathways, we analyzed changes in intra-cellular kinases implicated in metabolism, cell growth, physiology and pathology of hCAECs. Utilizing the Milliplex MAP multiple-pathway total and phosphorylated cell signaling 9-plex kits, we analyzed the following targets: CREB, JNK, NFkB, p38, ERK1/2, Akt, p70 S6 kinase, STAT3, and STAT5. To our surprise, NP-6A4 treatment did not alter the total protein for any of the targets in this passage of hCAECs (Figure 8E and Supplementary Figure 2). However, the phospho-protein assay showed that phospho-JNK showed a significant decrease compared to CTRL cells $(p<0.05$, Figure $8 \mathrm{E}$ ). Taken together, our data in hCAECs confirms that AT2R activation via NP$6 \mathrm{~A} 4$ is sufficient to promote cell growth, viability, and increase NO release. Although the exact mechanisms remain unresolved, future experiments will aim to uncover the intricacies involved in this response.

\section{DISCUSSION}

Here we show for the first time that the AT2R peptide agonist, NP-6A4, increases the expression levels of both Agtr2 mRNA and AT2R protein and activates a positive feed-back loop for AT2R signaling in hCAVSMCs and endothelial cells in vitro. As a direct result, downstream signaling is augmented, promoting an enhancement of NO signaling and mitochondrial bioenergetics. Important to the cardiovascular system, AT2R receptors are expressed on both endothelial and vascular smooth muscle cells and have been identified in rat small resistance arteries (Nora et al., 1998; Matrougui et al., 1999), and within mouse coronary arteries (Akishita et al., 2000; Wu et al., 2002). In 


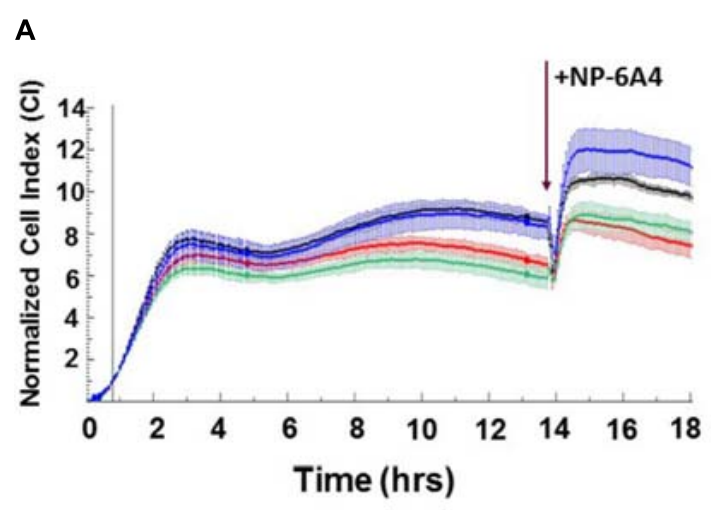

B Before NP-6A4

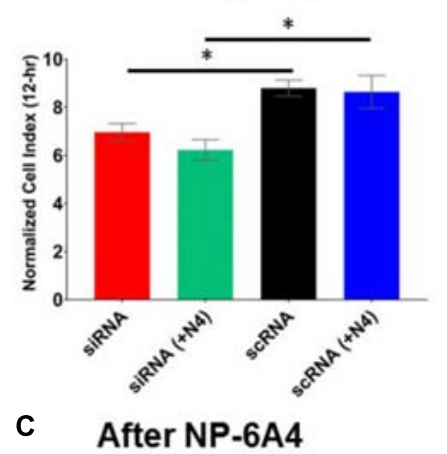

C After NP-6A4

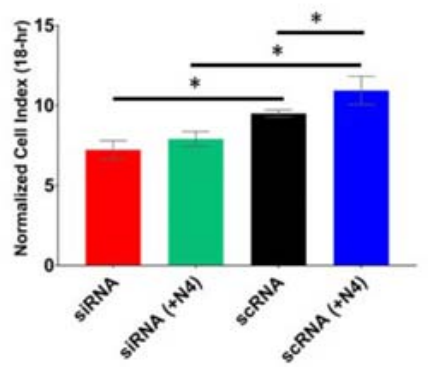

FIGURE 7 | AT2R siRNA inhibited growth properties (Cl) of hCAEC both in the absence and presence of NP-6A4. (A) Cell Index curve depicting change in cell index (Cl). Arrow indicates addition of NP-6A4. (B) Differences in $\mathrm{Cl}$ after $12 \mathrm{~h}$ of treatment with anti-AT2R siRNA (labeled siRNA) or siRNA-Scrambled (scRNA). At this point none of the cells had been treated with NP-6A4. $n=4$ per group. (C) Differences in Cl approximately 4 -h after the addition of NP-6A4 (20 $\mu$ M). $n=4$ per group. *Indicates $p<0.05$ vs. CTRL using one-way ANOVA at the indicated time points.

human pulmonary microvascular endothelial cells (HPMEC), Agtr2 mRNA was not detected under normal conditions or in response to LPS injury (Li et al., 2015), while Agtr1 mRNA was increased after LPS. While AT2R-agonists, specifically Compound 21, and to a lesser extent CGP42112, have been reported to confer beneficial effects in ex vivo and in vivo models (Ewert et al., 2003; Bosnyak et al., 2010; Rehman et al., 2012; Sampson et al., 2016), there have been no reports of either AT2R agonist having the ability to augment AT2R expression levels either at the mRNA or protein levels.

Using NP-6A4, we consistently demonstrate an increase in Agtr2 mRNA, ranging from two- to eightfold in cardiovascular cells. Interestingly, hCAVSMCs showed the increase after short (12-h) and long-term (7-days) of NP-6A4 treatment. This is in contrast to both endothelial cell types studied, whereby 12-h NP-6A4 treatment was insufficient to augment mRNA levels, but in both hCAEC and hUVECs, the 7day treatment showed a significant increase. Collectively, this suggests that the activation of AT2R and subsequent alterations in transcription and translation are uniquely regulated in hECs compared to hVSMCs. Although 12-h of NP-6A4 increased AT2R protein in all three cell types, hCAECs experienced the largest fold-increase compared to control, with a 2 .0-fold increase. Albeit no AT2R agonist has been shown to increase AT2R, in a model of ischemiareperfusion in isolated rat hearts, the AT1R-blocker Candesartan offered cardio protection through increased AT2R receptors, providing alternative means whereby an increase in AT2R in achieved and confers cardioprotection (Moudgil et al., 2002).

To our knowledge, our data is the first to show that AT2R upregulation via an AT2R agonist increased cellular oxygen consumption rates in hCAVSMCs. Historically, RAS has been defined as a circulating system involved in the maintenance of blood pressure through renal and vascular mechanisms (Gwathmey et al., 2012). Notwithstanding, recent studies have shown that local and intracellular RAS within specific cellular compartments may be responsible for numerous regulatory effects of Ang II (De Mello, 1994; Filipeanu et al., 2001; Re, 2007). Nuclear and mitochondrial RAS are involved with NO production (Gwathmey et al., 2012), and mitochondrial respiration (Abadir et al., 2011). Our data is in contrast to the current literature that shows in isolated mitochondria, decreased oxygen consumption after treatment with the AT2Ragonist CGP421140 (Abadir et al., 2011). Additionally, in HL-1 mouse cardiomyocytes, Ang II decreased oxygen consumption rates, supporting the notion that activation of RAS, either at the mitochondria or the whole cell level, may decrease oxygen consumption (Kim et al., 2017). There are differences between these reports and ours worth noting. Firstly, the use of isolated mitochondria vs. whole cell respiration measurements, and second, the AT2R agonist used, CGP421140 and Ang II vs. NP-6A4. Additionally, the longer duration of treatment in our studies likely had an effect on the ability of NP-6A4 to augment mitochondrial respiration. Furthermore, we cannot rule out that the source of cellular respiration is solely via 

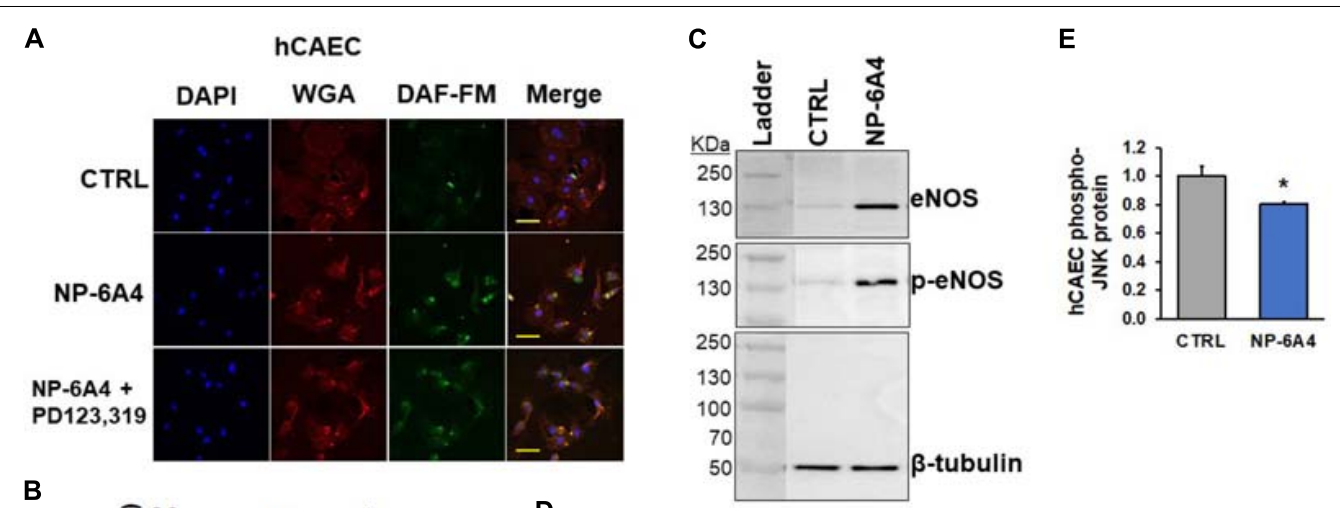

B
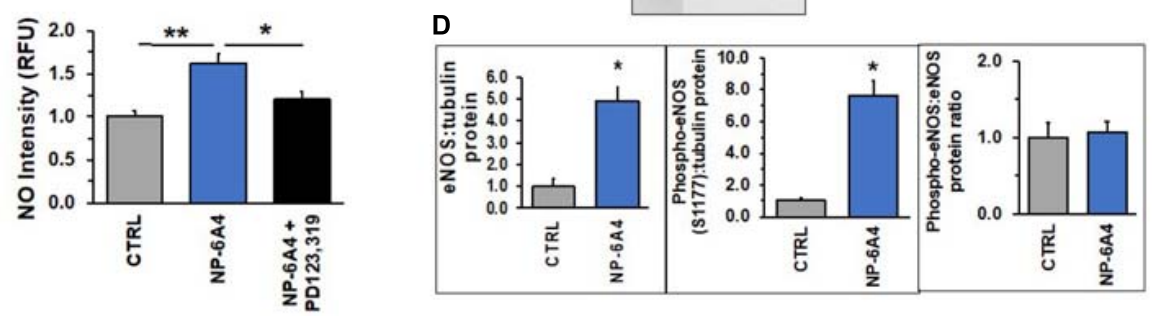

FIGURE 8 | NP-6A4 promotes cellular protective signaling in hCAECs. (A) Representative images of DAF-FM diacetate staining in hCAEC. Blue DAPI images show nuclei, Red wheat germ agglutinin (WGA) images show endothelial cell membrane, Green DAF-FM images show presence of detectable nitric oxide, and lastly, merged images show al three colors on one image. $n=3$. (B) Quantification of detectable NO showed that $5 \mu$ M NP-6A4 for 24 h increased NO, while PD123319 pretreatment prevented the increase. Fluorescent staining experiments consisted of quantification of $>50$ cells from triplicates. (C) Representative western blot images of eNOS and phospho-eNOS protein. (D) Quantification of eNOS and phosphos-eNOS show increased expression of eNOS after $12-h$ of $1 \mu M$ NP-6A4 treatment. The total to phospho-eNOS ratio was not affected. $n=4$. (E) $5 \mu \mathrm{M} \mathrm{NP-6A4} \mathrm{of} \mathrm{hCAEC} \mathrm{for} \mathrm{24-h} \mathrm{decreased} \mathrm{phosphorylated-JNK} \mathrm{as} \mathrm{determined} \mathrm{by} \mathrm{the}$ Milliplex MAP Multi-Pathway Total and Phospho- Magnetic Bead 9-Plex Assay. **Indicates difference from CTRL and *Indicates difference from NP-6A4-treated at $p<0.05$ using One-way ANOVA. Yellow scale bar = 100 microns. hCAEC, human coronary artery endothelial cell; DAF-FM = 4-Amino-5-Methylamino-2', $7^{\prime}-$ Difluorofluorescein Diacetate.

the mitochondria, as others suggest that oxygen consumption originating at the cell surface involving cellular NADH lends support to non-mitochondrial sources of oxygen consumption (Herst and Berridge, 2007). Lastly, our data suggests that the increase in oxygen consumption is not due to an increase in mitochondrial quantity, given that mtDNA and mitochondrial oxidative phosphorylation complexes were not significantly increased.

Reactive oxygen species (ROSs) are a class of gaseous signaling molecules related to NO. It is well accepted that the uncoupling of the mitochondrial respiratory chain and activation by cytosolic NADPH-oxidase contribute to ROS generation (Bellin et al., 2006). Doxorubicin (DOXO) is an anthracycline chemotherapeutic drug that is known to increase ROSs (Minotti et al., 2004; Kim et al., 2006) in various cell types including cardiomyocytes (Kim et al., 2006) and endothelial cells (Sonowal et al., 2018). Furthermore, the widely used chemotherapeutic anthracycline, DOXO, is known to attenuate beneficial eNOS signaling and resultant increase in NO release from endothelial cells (Sonowal et al., 2018). Our observation that DOXO treatment increases ROS in hCAVSMCs is in agreement with previous studies on the effect of DOXO treatment on other cell types. However, our observation that NP-6A4 treatment could reduce ROS levels in hCAVSMCs treated with DOXO suggests that NP-6A4 may exert protective effects on CAVSMCs in the presence of DOXO treatment.
It has been reported that Ang II, acting through AT2R, induces apoptosis in hUVECs and implicated AT2R-signaling in their dysfunction (Dimmeler et al., 1997). Alternatively, others have shown that in mouse VSMCs, AT2R activation neither increased eNOS phosphorylation via ser1177, nor changed plasma NO in $\operatorname{ApoE}^{(-/-)}$mice (Li et al., 2016). Further evidence shows that some of the beneficial effects of AT2R are mediated via bradykinin and nitric oxide (NO) system (Liu et al., 1997; Gohlke et al., 1998). NP-6A4 treatment did not enhance the growth characteristics of hCAECs. This is in contrast to the hCAVSMC response to NP-6A4 (Figure 4A), that showed an increased cell index and thus a positive response to cell growth conditions, with doses up to $20 \mu \mathrm{M}$. However, treatment with the AT2Ragonist PD123319 attenuated the CI of hCAECs, indicating that inhibition of AT2R is detrimental to the cells. Taken together, this suggests that hCAVSMCs and hCAECs demonstrate differential response to activation of AT2R signaling by NP-6A4, with the latter showing no response in cell index.

Endothelial cells lining the coronary artery are essential for regulation of coronary blood flow and overall cardiac functions, implicating them in injury and disease conditions. Given that hCAECs are known to have higher expression of AT1R compared to AT2R (Li et al., 1999), the ability of NP-6A4 to increase the expression of AT2R mRNA and protein is a critical feature of this drug's pharmacodynamics. Our data is the first to show that using an AT2R agonist, eNOS and NO levels can be augmented 
in hCAECs. In one study, NO release was improved via activation of the bradykinin system via AT2R stimulation (Harada et al., 2002). However, these experiments were performed in isolated aortic endothelial cells from spontaneously hypertensive WKY rats and through the use of Losartan to block AT1R (which allow for increased AT2R activation). Notwithstanding, this data lends support to our findings using coronary artery endothelial cells, that increased AT2R-signaling can augment NO-signaling.

These studies provide the first evidence that an AT2R agonist can increase the expression of Agtr2 mRNA and AT2R protein in cardiovascular cells. Importantly, downstream cellular protective AT2R signaling is augmented while NP-6A4 does not cause cell toxicity. Vascular smooth muscle cells responded via increased cellular respiration, suggesting that NP-6A4-AT2R signaling can enhance mitochondrial energy dynamics. Likewise, NP-6A4 doses up to $20 \mu \mathrm{M}$ did not cause any growth arresting side effects. Endothelial cells responded to NP-6A4-induced AT2R activation via increased eNOS signaling and higher levels of NO.

\section{AUTHOR CONTRIBUTIONS}

RT and LP developed conceptual ideas and design. RT carried out the experiments, data analysis, figure generation, and wrote the manuscript. AB carried out Milliplex MAP Multi-Pathway Total and Phospho-Magnetic Bead 9-Plex Assay, data analysis, figure generation, and manuscript editing. All authors approved the final version of the manuscript.

\section{REFERENCES}

Abadir, P. M., Foster, D. B., Crow, M., Cooke, C. A., Rucker, J. J., Jain, A., et al. (2011). Identification and characterization of a functional mitochondrial angiotensin system. Proc. Natl. Acad. Sci. U.S.A. 108, 14849-14854. doi: 10.1073/pnas.1101507108

Akishita, M., Horiuchi, M., Yamada, H., Zhang, L., Shirakami, G., Tamura, K., et al. (2000). Inflammation influences vascular remodeling through AT2 receptor expression and signaling. Physiol. Genomics 2, 13-20. doi: 10.1152/ physiolgenomics.2000.2.1.13

Ali, Q., Wu, Y., and Hussain, T. (2013). Chronic AT2 receptor activation increases renal ACE2 activity, attenuates AT1 receptor function and blood pressure in obese Zucker rats. Kidney Int. 84, 931-939. doi: 10.1038/ki. 2013.193

Altarche-Xifro, W., Curato, C., Kaschina, E., Grzesiak, A., Slavic, S., Dong, J., et al. (2009). Cardiac c-kit+AT2 + cell population is increased in response to ischemic injury and supports cardiomyocyte performance. Stem Cells 27, 2488-2497. doi: 10.1002/stem.171

Asensio-Lopez, M. C., Soler, F., Pascual-Figal, D., Fernandez-Belda, F., and Lax, A. (2017). Doxorubicin-induced oxidative stress: the protective effect of nicorandil on HL-1 cardiomyocytes. PLoS One 12:e0172803. doi: 10.1371/journal.pone. 0172803

Axelsson, A., Iversen, K., Vejlstrup, N., Ho, C., Norsk, J., Langhoff, L., et al. (2015). Efficacy and safety of the angiotensin II receptor blocker losartan for hypertrophic cardiomyopathy: the INHERIT randomised, double-blind, placebo-controlled trial. Lancet Diabetes Endocrinol. 3, 123-131. doi: 10.1016/ S2213-8587(14)70241-4

Axelsson, A., Iversen, K., Vejlstrup, N., Ho, C. Y., Havndrup, O., Kofoed, K. F., et al. (2016). Functional effects of losartan in hypertrophic cardiomyopathya randomised clinical trial. Heart 102, 285-291. doi: 10.1136/heartjnl-2015308343

Bellin, C., de Wiza, D. H., Wiernsperger, N. F., and Rosen, P. (2006). Generation of reactive oxygen species by endothelial and smooth muscle cells: influence of

\section{FUNDING}

This work was supported, in part, by the Life Science Mission Enhancement Fund from UM-Columbia (LP), NIH NHLBI 1R01HL118376-01 (LP), NIH NHLBI 1R01HL13898801A1 (LP), and a small grant from Novopyxis, Boston, MA, United States.

\section{ACKNOWLEDGMENTS}

We greatly acknowledge the facilities at Dalton Cardiovascular Research Center. We are grateful to Dr. Luis Martinez-Lemus Lab for assistance with DAFFM staining and microscopy and Dr. Scott Rector and Grace Meers for assisting with Seahorse Extracellular Flux Analyzer experiments. We also thank Dr. Kevin Fritsche Lab for assisting with the using $\mathrm{xMAP}^{\circledR}$ technology on MAGPIX ${ }^{\circledR}$ platform (Luminex, Austin, TX, United States).

\section{SUPPLEMENTARY MATERIAL}

The Supplementary Material for this article can be found online at: https://www.frontiersin.org/articles/10.3389/fphar. 2018.00928/full\#supplementary-material

hyperglycemia and metformin. Horm. Metab. Res. 38, 732-739. doi: 10.1055/s2006-955084

Bielak-Zmijewska, A., Wnuk, M., Przybylska, D., Grabowska, W., Lewinska, A., Alster, O., et al. (2014). A comparison of replicative senescence and doxorubicin-induced premature senescence of vascular smooth muscle cells isolated from human aorta. Biogerontology 15, 47-64. doi: 10.1007/s10522-0139477-9

Borghi, C., Force, S. T., Rossi, F., and Force, S. I. F. T. (2015). Role of the renin-angiotensin-aldosterone system and its pharmacological inhibitors in cardiovascular diseases: complex and critical issues. High Blood Press. Cardiovasc. Prev. 22, 429-444. doi: 10.1007/s40292-0150120-5

Bosnyak, S., Welungoda, I. K., Hallberg, A., Alterman, M., Widdop, R. E., and Jones, E. S. (2010). Stimulation of angiotensin AT2 receptors by the nonpeptide agonist, Compound 21, evokes vasodepressor effects in conscious spontaneously hypertensive rats. Br. J. Pharmacol. 159, 709-716. doi: 10.1111/j. 1476-5381.2009.00575.x

Chow, B. S., Koulis, C., Krishnaswamy, P., Steckelings, U. M., Unger, T., Cooper, M. E., et al. (2016). The angiotensin II type 2 receptor agonist Compound 21 is protective in experimental diabetes-associated atherosclerosis. Diabetologia 59, 1778-1790. doi: 10.1007/s00125-016-3977-5

Cortassa, S., Sollott, S. J., and Aon, M. A. (2017). Mitochondrial respiration and ROS emission during beta-oxidation in the heart: an experimentalcomputational study. PLoS Comput. Biol. 13:e1005588. doi: 10.1371/journal. pcbi. 1005588

Curato, C., Slavic, S., Dong, J., Skorska, A., Altarche-Xifro, W., Miteva, K., et al. (2010). Identification of noncytotoxic and IL-10-producing CD8+AT2R+ T cell population in response to ischemic heart injury. J. Immunol. 185, 62866293. doi: 10.4049/jimmunol.0903681

Daugherty, A., Rateri, D. L., Howatt, D. A., Charnigo, R., and Cassis, L. A. (2013). PD123319 augments angiotensin II-induced abdominal aortic aneurysms through an AT2 receptor-independent mechanism. PLoS One 8:e61849. doi: 10.1371/journal.pone.0061849 
De Mello, W. C. (1994). Is an intracellular renin-angiotensin system involved in control of cell communication in heart? J. Cardiovasc. Pharmacol. 23, 640-646. doi: 10.1097/00005344-199404000-00018

Di, M., Wang, L., Li, M., Zhang, Y., Liu, X., Zeng, R., et al. (2017). Dickkopf1 destabilizes atherosclerotic plaques and promotes plaque formation by inducing apoptosis of endothelial cells through activation of ER stress. Cell Death Dis. 8:e2917. doi: 10.1038/cddis.2017.277

Dimmeler, S., Rippmann, V., Weiland, U., Haendeler, J., and Zeiher, A. M. (1997). Angiotensin II induces apoptosis of human endothelial cells. Protective effect of nitric oxide. Circ. Res. 81, 970-976. doi: 10.1161/01.RES.81.6.970

Ewert, S., Laesser, M., Johansson, B., Holm, M., Aneman, A., and Fandriks, L. (2003). The angiotensin II receptor type 2 agonist CGP 42112A stimulates NO production in the porcine jejunal mucosa. BMC Pharmacol. 3:2. doi: 10.1186/ 1471-2210-3-2

Ferrario, C. M., and Strawn, W. B. (2006). Role of the renin-angiotensinaldosterone system and proinflammatory mediators in cardiovascular disease. Am. J. Cardiol. 98, 121-128. doi: 10.1016/j.amjcard.2006.01.059

Filipeanu, C. M., Henning, R. H., de Zeeuw, D., and Nelemans, A. (2001). Intracellular angiotensin II and cell growth of vascular smooth muscle cells. $\mathrm{Br}$. J. Pharmacol. 132, 1590-1596. doi: 10.1038/sj.bjp.0703984

Fouda, A. Y., Pillai, B., Dhandapani, K. M., Ergul, A., and Fagan, S. C. (2017). Role of interleukin-10 in the neuroprotective effect of the angiotensin type 2 receptor agonist, compound 21, after ischemia/reperfusion injury. Eur. J. Pharmacol. 799, 128-134. doi: 10.1016/j.ejphar.2017.02.016

Gao, J., Zucker, I. H., and Gao, L. (2014). Activation of central angiotensin type 2 receptors by compound 21 improves arterial baroreflex sensitivity in rats with heart failure. Am. J. Hypertens. 27, 1248-1256. doi: 10.1093/ajh/hpu044

Gohlke, P., Pees, C., and Unger, T. (1998). AT2 receptor stimulation increases aortic cyclic GMP in SHRSP by a kinin-dependent mechanism. Hypertension 31(1 Pt 2), 349-355. doi: 10.1161/01.HYP.31.1.349

Gul, R., Ramdas, M., Mandavia, C. H., Sowers, J. R., and Pulakat, L. (2012). RAS-mediated adaptive mechanisms in cardiovascular tissues: confounding factors of ras blockade therapy and alternative approaches. Cardiorenal Med. 2, 268-280. doi: 10.1159/000343456

Gwathmey, T. M., Alzayadneh, E. M., Pendergrass, K. D., and Chappell, M. C. (2012). Novel roles of nuclear angiotensin receptors and signaling mechanisms. Am. J. Physiol. Regul. Integr. Comp. Physiol. 302, R518-R530. doi: 10.1152/ ajpregu.00525.2011

Harada, S., Nakata, T., Oguni, A., Kido, H., Hatta, T., Fukuyama, R., et al. (2002). Contrasting effects of angiotensin type 1 and 2 receptors on nitric oxide release under pressure. Hypertens. Res. 25, 779-786. doi: 10.1291/hypres.25.779

Herst, P. M., and Berridge, M. V. (2007). Cell surface oxygen consumption: a major contributor to cellular oxygen consumption in glycolytic cancer cell lines. Biochim. Biophys. Acta 1767, 170-177. doi: 10.1016/j.bbabio.2006.11.018

Inagami, T. (1994). The renin-angiotensin system. Essays Biochem. 28, 147-164.

Jensen, P. K. (1966). Antimycin-insensitive oxidation of succinate and reduced nicotinamide-adenine dinucleotide in electron-transport particles. I. $\mathrm{pH}$ dependency and hydrogen peroxide formation. Biochim. Biophys. Acta 122, 157-166. doi: 10.1016/0926-6593(66)90057-9

Jones, E. S., Vinh, A., McCarthy, C. A., Gaspari, T. A., and Widdop, R. E. (2008). AT2 receptors: functional relevance in cardiovascular disease. Pharmacol. Ther. 120, 292-316. doi: 10.1016/j.pharmthera.2008.08.009

Kambayashi, Y., Bardhan, S., Takahashi, K., Tsuzuki, S., Inui, H., Hamakubo, T., et al. (1993). Molecular cloning of a novel angiotensin II receptor isoform involved in phosphotyrosine phosphatase inhibition. J. Biol. Chem. 268, 2454324546.

Khaddaj Mallat, R., Mathew John, C., Kendrick, D. J., and Braun, A. P. (2017). The vascular endothelium: a regulator of arterial tone and interface for the immune system. Crit. Rev. Clin. Lab. Sci. 54, 458-470. doi: 10.1080/10408363. 2017.1394267

Kijima, K., Matsubara, H., Murasawa, S., Maruyama, K., Mori, Y., and Inada, M. (1995). Gene transcription of angiotensin II type 2 receptor is repressed by growth factors and glucocorticoids in PC12 cells. Biochem. Biophys. Res. Commun. 216, 359-366. doi: 10.1006/bbrc.1995.2632

Kim, N., Jung, Y., Nam, M., Sun Kang, M., Lee, M. K., Cho, Y., et al. (2017). Angiotensin II affects inflammation mechanisms via AMPK-related signalling pathways in HL-1 atrial myocytes. Sci. Rep. 7:10328. doi: 10.1038/s41598-01709675-3
Kim, S. Y., Kim, S. J., Kim, B. J., Rah, S. Y., Chung, S. M., Im, M. J., et al. (2006). Doxorubicin-induced reactive oxygen species generation and intracellular $\mathrm{Ca} 2+$ increase are reciprocally modulated in rat cardiomyocytes. Exp. Mol. Med. 38, 535-545. doi: 10.1038/emm.2006.63

Kumar, V., Knowle, D., Gavini, N., and Pulakat, L. (2002). Identification of the region of AT2 receptor needed for inhibition of the AT1 receptor-mediated inositol 1,4,5-triphosphate generation. FEBS Lett. 532, 379-386. doi: 10.1016/ S0014-5793(02)03713-4

Kurisu, S., Ozono, R., Oshima, T., Kambe, M., Ishida, T., Sugino, H., et al. (2003). Cardiac angiotensin II type 2 receptor activates the kinin/NO system and inhibits fibrosis. Hypertension 41, 99-107. doi: 10.1161/01.HYP.0000050101. 90932.14

Li, D. Y., Zhang, Y. C., Philips, M. I., Sawamura, T., and Mehta, J. L. (1999). Upregulation of endothelial receptor for oxidized low-density lipoprotein (LOX-1) in cultured human coronary artery endothelial cells by angiotensin II type 1 receptor activation. Circ. Res. 84, 1043-1049. doi: 10.1161/01.RES.84. 9.1043

Li, H. P., Qiu, H. B., and Wang, H. Q. (2015). Effect of lipopolysaccharide on angiotensin II type 1 receptor expression and function in human pulmonary microvascular endothelial cells. Mol. Med. Rep. 12, 8289-8293. doi: 10.3892/ mmr.2015.4481

Li, J., Culman, J., Hortnagl, H., Zhao, Y., Gerova, N., Timm, M., et al. (2005). Angiotensin AT2 receptor protects against cerebral ischemia-induced neuronal injury. FASEB J. 19, 617-619. doi: 10.1096/fj.04-2960fje

Li, M., Tejada, T., Lambert, J. P., Nicholson, C. K., Yahiro, E., Ambai, V. T., et al. (2016). Angiotensin type 2-receptor (AT2R) activation induces hypotension in apolipoprotein E-deficient mice by activating peroxisome proliferator-activated receptor-gamma. Am. J. Cardiovasc. Dis. 6, 118-128.

Liu, Y. H., Yang, X. P., Sharov, V. G., Nass, O., Sabbah, H. N., Peterson, E., et al. (1997). Effects of angiotensin-converting enzyme inhibitors and angiotensin II type 1 receptor antagonists in rats with heart failure. Role of kinins and angiotensin II type 2 receptors. J. Clin. Invest. 99, 1926-1935. doi: 10.1172/ JCI119360

Ludwig, M., Steinhoff, G., and Li, J. (2012). The regenerative potential of angiotensin AT2 receptor in cardiac repair. Can. J. Physiol. Pharmacol. 90, 287-293. doi: 10.1139/y11-108

Lum-Naihe, K. T., Toedebusch, R., Mahmood, A., Bajwa, J., Carmack, T., Kumar, S., et al. (2017). Cardiovascular disease progression in female Zucker Diabetic Fatty rats occurs via unique mechanisms compared to males. Sci. Rep. 7:17823. doi: 10.1038/s41598-017-18003-8

Mahmood, A., and Pulakat, L. (2015). Differential effects of beta-blockers, angiotensin ii receptor blockers, and a novel AT2R agonist NP-6A4 on stress response of nutrient-starved cardiovascular cells. PLoS One 10:e144824. doi: 10.1371/journal.pone.0144824

Masaki, H., Kurihara, T., Yamaki, A., Inomata, N., Nozawa, Y., Mori, Y., et al. (1998). Cardiac-specific overexpression of angiotensin II AT2 receptor causes attenuated response to AT1 receptor-mediated pressor and chronotropic effects. J. Clin. Invest. 101, 527-535. doi: 10.1172/ JCI1885

Matavelli, L. C., Zatz, R., and Siragy, H. M. (2015). A nonpeptide angiotensin II type 2 receptor agonist prevents renal inflammation in early diabetes. J. Cardiovasc. Pharmacol. 65, 371-376. doi: 10.1097/FJC.0000000000000207

Matrougui, K., Loufrani, L., Heymes, C., Levy, B. I., and Henrion, D. (1999). Activation of AT(2) receptors by endogenous angiotensin II is involved in flowinduced dilation in rat resistance arteries. Hypertension 34(4 Pt 1), 659-665. doi: 10.1161/01.HYP.34.4.659

McCarthy, C. A., Vinh, A., Miller, A. A., Hallberg, A., Alterman, M., Callaway, J. K., et al. (2014). Direct angiotensin AT2 receptor stimulation using a novel AT2 receptor agonist, compound 21, evokes neuroprotection in conscious hypertensive rats. PLoS One 9:e95762. doi: 10.1371/journal.pone. 0095762

Minotti, G., Menna, P., Salvatorelli, E., Cairo, G., and Gianni, L. (2004). Anthracyclines: molecular advances and pharmacologic developments in antitumor activity and cardiotoxicity. Pharmacol. Rev. 56, 185-229. doi: 10.1124/pr.56.2.6

Miyata, N., Park, F., Li, X. F., and Cowley, A. W. Jr. (1999). Distribution of angiotensin AT1 and AT2 receptor subtypes in the rat kidney. Am. J. Physiol. 277(3 Pt 2), F437-F446. doi: 10.1152/ajprenal.1999.277.3.F437 
Moudgil, R., Musat-Marcu, S., Xu, Y., Kumar, D., and Jugdutt, B. I. (2002). Increased $\mathrm{AT}(2) \mathrm{R}$ protein expression but not increased apoptosis during cardioprotection induced by AT(1)R blockade. Can. J. Cardiol. 18, 1107-1116.

Mukoyama, M., Nakajima, M., Horiuchi, M., Sasamura, H., Pratt, R. E., and Dzau, V. J. (1993). Expression cloning of type 2 angiotensin II receptor reveals a unique class of seven-transmembrane receptors. J. Biol. Chem. 268, 24539-24542.

Nguyen Dinh Cat, A., Montezano, A. C., Burger, D., and Touyz, R. M. (2013). Angiotensin II, NADPH oxidase, and redox signaling in the vasculature. Antioxid. Redox Signal. 19, 1110-1120. doi: 10.1089/ars.2012.4641

Nora, E. H., Munzenmaier, D. H., Hansen-Smith, F. M., Lombard, J. H., and Greene, A. S. (1998). Localization of the ANG II type 2 receptor in the microcirculation of skeletal muscle. Am. J. Physiol. 275(4 Pt 2), H1395-H1403. doi: 10.1152/ajpheart.1998.275.4.H1395

Oishi, Y., Ozono, R., Yoshizumi, M., Akishita, M., Horiuchi, M., and Oshima, T. (2006). AT2 receptor mediates the cardioprotective effects of AT1 receptor antagonist in post-myocardial infarction remodeling. Life Sci. 80, 82-88. doi: 10.1016/j.lfs.2006.08.033

Okumura, M., Iwai, M., Ide, A., Mogi, M., Ito, M., and Horiuchi, M. (2005). Sex difference in vascular injury and the vasoprotective effect of valsartan are related to differential AT2 receptor expression. Hypertension 46, 577-583. doi: 10.1161/01.HYP.0000178564.14464.80

Padia, S. H., and Carey, R. M. (2013). AT2 receptors: beneficial counterregulatory role in cardiovascular and renal function. Pflugers Arch. 465, 99-110. doi: 10.1007/s00424-012-1146-3

Pandey, A., and Gaikwad, A. B. (2017). Compound 21 and telmisartan combination mitigates type 2 diabetic nephropathy through amelioration of caspase mediated apoptosis. Biochem. Biophys. Res. Commun. 487, 827-833. doi: 10.1016/j.bbrc.2017.04.134

Peluso, A. A., Bertelsen, J. B., Andersen, K., Mortsensen, T. P., Hansen, P. B., Sumners, C., et al. (2018). Identification of protein phosphatase involvement in the AT2 receptor-induced activation of endothelial nitric oxide synthase. Clin. Sci. 132, 777-790. doi: 10.1042/CS20171598

Prieto, D., Contreras, C., and Sanchez, A. (2014). Endothelial dysfunction, obesity and insulin resistance. Curr. Vasc. Pharmacol. 12, 412-426. doi: 10.2174/ 1570161112666140423221008

Re, R. (2007). Intracellular renin-angiotensin system: the tip of the intracrine physiology iceberg. Am. J. Physiol. Heart Circ. Physiol. 293, H905-H906. doi: 10.1152/ajpheart.00552.2007

Rehman, A., Leibowitz, A., Yamamoto, N., Rautureau, Y., Paradis, P., and Schiffrin, E. L. (2012). Angiotensin type 2 receptor agonist compound 21 reduces vascular injury and myocardial fibrosis in stroke-prone spontaneously hypertensive rats. Hypertension 59, 291-299. doi: 10.1161/HYPERTENSIONAHA.111.180158

Sadoshima, J., and Izumo, S. (1993). Molecular characterization of angiotensin II-induced hypertrophy of cardiac myocytes and hyperplasia of cardiac fibroblasts. Critical role of the AT1 receptor subtype. Circ. Res. 73, 413-423. doi: 10.1161/01.RES.73.3.413

Sampson, A. K., Irvine, J. C., Shihata, W. A., Dragoljevic, D., Lumsden, N., Huet, O., et al. (2016). Compound 21, a selective agonist of angiotensin AT2 receptors, prevents endothelial inflammation and leukocyte adhesion in vitro and in vivo. Br. J. Pharmacol. 173, 729-740. doi: 10.1111/bph.13063
Sampson, A. K., Moritz, K. M., Jones, E. S., Flower, R. L., Widdop, R. E., and Denton, K. M. (2008). Enhanced angiotensin II type 2 receptor mechanisms mediate decreases in arterial pressure attributable to chronic lowdose angiotensin II in female rats. Hypertension 52, 666-671. doi: 10.1161/ HYPERTENSIONAHA.108.114058

Sonowal, H., Pal, P., Shukla, K., Saxena, A., Srivastava, S. K., and Ramana, K. V. (2018). Aldose reductase inhibitor, fidarestat prevents doxorubicin-induced endothelial cell death and dysfunction. Biochem. Pharmacol. 150, 181-190. doi: 10.1016/j.bcp.2018.02.018

Wang, Z. Q., Moore, A. F., Ozono, R., Siragy, H. M., and Carey, R. M. (1998). Immunolocalization of subtype 2 angiotensin II (AT2) receptor protein in rat heart. Hypertension 32, 78-83. doi: 10.1161/01.HYP.32.1.78

Widdop, R. E., Jones, E. S., Hannan, R. E., and Gaspari, T. A. (2003). Angiotensin AT2 receptors: cardiovascular hope or hype? Br. J. Pharmacol. 140, 809-824. doi: $10.1038 /$ sj.bjp. 0705448

World Health Organization [WHO] (2017). Cardiovascular Diseases (CVD). Available at: http://www.who.int/mediacentre/factsheets/fs317/en/

Wu, L., Iwai, M., Nakagami, H., Chen, R., Suzuki, J., Akishita, M., et al. (2002). Effect of angiotensin II type 1 receptor blockade on cardiac remodeling in angiotensin II type 2 receptor null mice. Arterioscler. Thromb. Vasc. Biol. 22, 49-54. doi: 10.1161/hq0102.102277

Xu, J., Sun, Y., Carretero, O. A., Zhu, L., Harding, P., Shesely, E. G., et al. (2014). Effects of cardiac overexpression of the angiotensin II type 2 receptor on remodeling and dysfunction in mice post-myocardial infarction. Hypertension 63, 1251-1259. doi: 10.1161/HYPERTENSIONAHA.114.03247

Yang, J., Chen, C., Ren, H., Han, Y., He, D., Zhou, L., et al. (2012). Angiotensin II AT(2) receptor decreases AT(1) receptor expression and function via nitric oxide/cGMP/Sp1 in renal proximal tubule cells from Wistar-Kyoto rats. J. Hypertens. 30, 1176-1184. doi: 10.1097/HJH.0b013e32835 32099

Yayama, K., and Okamoto, H. (2008). Angiotensin II-induced vasodilation via type 2 receptor: role of bradykinin and nitric oxide. Int. Immunopharmacol. 8, 312-318. doi: 10.1016/j.intimp.2007.06.012

Zhu, L., Carretero, O. A., Liao, T. D., Harding, P., Li, H., Sumners, C., et al. (2010). Role of prolylcarboxypeptidase in angiotensin II type 2 receptor-mediated bradykinin release in mouse coronary artery endothelial cells. Hypertension 56, 384-390. doi: 10.1161/HYPERTENSIONAHA.110.155051

Conflict of Interest Statement: The authors declare that the research was conducted in the absence of any commercial or financial relationships that could be construed as a potential conflict of interest.

The reviewer PB and handling Editor declared their shared affiliation.

Copyright (c) 2018 Toedebusch, Belenchia and Pulakat. This is an open-access article distributed under the terms of the Creative Commons Attribution License (CC BY). The use, distribution or reproduction in other forums is permitted, provided the original author(s) and the copyright owner(s) are credited and that the original publication in this journal is cited, in accordance with accepted academic practice. No use, distribution or reproduction is permitted which does not comply with these terms. 